\title{
Genetic background of supernumerary teeth
}

\author{
Aslı Subasioglu ${ }^{1}$, Selcuk Savas ${ }^{2}$, Ebru Kucukyilmaz ${ }^{2}$, Servet Kesim ${ }^{3}$, Ahmet Yagci $^{4}$, \\ Munis Dundar ${ }^{5}$
}

Correspondence: Dr. Munis Dundar

Email: dundar@erciyes.edu.tr

\begin{abstract}
'Department of Medical Genetics, Izmir Katip Celebi University, Ataturk Training and Research Hospital, Izmir, Turkiye,

${ }^{2}$ Department of Pedodontics, Dentistry Faculty, Izmir Katip Celebi University, Izmir, Turkiye,

${ }^{3}$ Department of Periodontology, Faculty of Dentistry, Erciyes University, Kayseri, Turkiye,

${ }^{4}$ Department of Orthodontics, Faculty of Dentistry, Erciyes University, Kayseri, Turkiye,

${ }^{5}$ Department of Medical Genetics, Medical Faculty, Erciyes University, Kayseri, Turkiye
\end{abstract}

\section{ABSTRACT}

Supernumerary teeth (ST) are odontostomatologic anomaly characterized by as the existence excessive number of teeth in relation to the normal dental formula. This condition is commonly seen with several congenital genetic disorders such as Gardner's syndrome, cleidocranial dysostosis and cleft lip and palate. Less common syndromes that are associated with ST are; Fabry Disease, Ellis-van Creveld syndrome, Nance-Horan syndrome, Rubinstein-Taybi Syndrome and Trico-Rhino-Phalangeal syndrome. ST can be an important component of a distinctive disorder and an important clue for early diagnosis. Certainly early detecting the abnormalities gives us to make correct management of the patient and also it is important for making well-informed decisions about long-term medical care and treatment. In this review, the genetic syndromes that are related with ST were discussed.

Key words: Dental anomalies, genetic syndromes, supernumerary teeth

\section{INTRODUCTION}

Both the primary and permanent dentitions may be affected by variations in the number, size, and form of the teeth, as well as the structure of the dental hard tissues. ${ }^{[1]}$ These variations may be caused by local or systemically acting environmental factors and genetically determined, or possibly from a combination of both two factors. ${ }^{[2-4]}$ Dental anomalies classified as numerical, form, size, structural, and positional anomalies, and supernumerary teeth (ST) have an important place in numerical anomalies. ${ }^{[5]}$

Supernumerary teeth or hyperdontia are odontostomatologic anomaly characterized by as the existence of an excessive number of teeth. ${ }^{[6]}$ The prevalence of ST has been reported $0.2-3 \%$ in the primary and permanent dentition. ${ }^{[7,8]}$ Supernumerary primary teeth are apparently less common than supernumerary permanent teeth and patients with supernumerary primary teeth have a 30-50\% chance of these being followed by supernumerary permanent teeth. ${ }^{[9-11]}$ The anomaly effect the maxilla more than the mandible $(8: 1) \cdot{ }^{[12,13]}$ Bruning et al. ${ }^{[11]}$ suggested a sex-linked inheritance pattern; males over females. ST may develop at any location, but mostly at the premaxillar region. ${ }^{[14]}$ Moreover, excessive teeth between two maxillary incisors are referred as mesiodens and ST in the molar regions adjacent or distal to the normal sequence of teeth are referred to as paramolars or distomolars, respectively. ${ }^{[15,16]}$ ST might resemble normal teeth or be amorphous, in some cases they may be an odontome. ${ }^{[17]}$ Teeth that resemble those of the normal series are referred

How to cite this article: Subasioglu A, Savas S, Kucukyilmaz E, Kesim S, Yagci A, Dundar M. Genetic background of supernumerary teeth. Eur J Dent 2015;9:153-8.

Copyright $\odot 2015$ Dental Investigations Society. DOI: $10.4103 / 1305-7456.149670$ 
to as supplemental teeth while those of less typical, often reduced, form-sometimes further described as tuberculate or conical can be termed accessory ST. ${ }^{[18]}$

Eruption failure, rotation or displacement of the adjacent teeth, dilacerations, root resorption, crowding, malocclusion, fistulas and cystic formation, nasal cavity eruption, and delayed or abnormal root development of permanent teeth are common clinical complications linked with ST. ${ }^{[19-21]}$ A precise diagnosis of ST and its management requires clinical examination and a comprehensive radiographic screening just after that. ${ }^{[20,21]}$ Furthermore, the location and morphology of ST and other clinical complications will also affect the choice of the treatment and extraction of the teeth is the most common method for treatment. ${ }^{[15-18]}$

There are many numbers of theories about the development of the etiology of ST even though it's not fully explained. ${ }^{[18]}$ Hyperactivity of the dental lamina or dichotomy of the tooth bud, the molecular mechanism during the early phase of tooth development can be a ground for single ST. ${ }^{[19-21]}$ ST occur more commonly in the relatives of affected patients than in the general population. They can be transmitted as an autosomal dominant or autosomal recessive trait with incomplete penetrance, or may be associated with the $\mathrm{X}$ chromosom. ${ }^{[22]}$ Although there are some reports of multiple or bilaterally ST without any systemic conditions or associated syndromes, in most cases, ST are associated with other conditions or defects such as cleft lip/palate, cleidocranial dysostosis (CCD) and Gardner's syndrome. ${ }^{[22-26]}$ Less common syndromes that related with ST are; Fabry disease, Ellis-van Creveld (EvC) syndrome, Trico-Rhino-Phalangeal syndrome (TRPS), Rubinstein-Taybi Syndrome (RTS), and Nance-Horan syndrome (NHS). ${ }^{[27-31]}$ In this review, possible etiological factors and the genetic background of ST were identified.

\section{Cleft lip and palate}

Clefts of the lip-palate (CLP) are the most common congenital craniofacial deformities, resulting from incomplete fusion of the facial buds at the beginning of pregnancy. ${ }^{[32]}$ Genetic and environmental factors, as well as their interactions, have been implied in CLP etiology. CLP occurs in $15 \%$ of neonates in the homozygous A/WySn mouse strain, with a multifactorial genetic etiology, the clf1 and clf2 variant genes. The prevalence of the isolated cleft lip and isolated cleft palate is approximately $1 / 1000$ and
$1 / 2000$ respectively. ${ }^{[33,34]}$ The anodontia is the most common anomaly, which are found at the cleft area, ST are the second ones and both of them are seen nearly seven times more frequent in patients with orofacial cleft. ${ }^{[35]}$ The reason of the ST at the cleft area is the fragmentation of the dental lamina during cleft formation, and the frequency of ST in the cleft area is about $22.2 \%{ }^{[36]}$ Due to the anatomy of the cleft region, it is difficult to distinguish the ST from the others, clinicians should be aware the disorder and its sequels. In the treatment of this condition, a craniofacial team work together, and dentists play a critical role for the best outcomes.

\section{Cleidocranial dysostosis}

Cleidocranial dysostosis is a rare syndrome with autosomal dominant inheritance. The frequency of this disorder is one per million individuals. ${ }^{[37]}$ Although the usual pattern of inheritance is autosomal dominant, around $40 \%$ of cases can occur as sporadic. ${ }^{[38,39]}$ CCD has now been associated with more than 48 distinct phenotypic features, including central nervous system anomalies, axial and appendicular skeletal defects, craniofacial and dental malformations and hearing loss. ${ }^{[40-44]}$ Skeletal manifestations include hypoplastic or aplastic clavicle, abnormally large, wide-open fontanels at birth that may remain open throughout life, delayed eruption of primary teeth, ST with dental crowding, delayed eruption of secondary dentition, open pubic symphysis, short, broad thumbs, tapering fingers and brachydactyly. ${ }^{[40,41]}$ Scoliosis, genu valgum, and pes planus are other skeletal problems that seen in the CCD patients. Other features of the syndrome include abnormality of pharyngeal bones, maxillary and mandibular abnormalities, obliterated maxillary sinuses, crossed renal ectopia and pelvic abnormalities. ${ }^{[42,43]}$ The patients may show mild degree of motor delay. ${ }^{[40-43]}$ The affected gene has been located on chromosome $6 \mathrm{p} 21 .{ }^{[45]}$ Mundlos et al. identified mutations in CBF-1 (RUNX2) as the molecular etiology of CCD. ${ }^{[46]}$ To date, more than 70 mutations within the coding regions and splice sites of RUNX2 have been identified. ${ }^{[47]}$ At the syndrome, significant phenotypic variabilities are the rule. Some of the cases present with in utero fractures and severe calvarias hypomineralization or skeletal abnormalities, other manifest only ST. ${ }^{[42]}$ No definitive genotype-phenotype correlations have been identified. ${ }^{[22,43]}$ The frequencies of ST in patients with cleidocranial dysplasia are seen nearly $22 \%$ in the maxillary incisor region and $5 \%$ in the molar 
region. ${ }^{[48]}$ Although there is a variable expressivity of CCD early diagnosis through dysmorphic features and also oral findings are possible.

\section{Gardner's syndrome}

Gardner's syndrome is an autosomal dominant genetic disorder with complete penetrance and variable expressivity. ${ }^{[49]}$ The characteristic features of the syndrome are; multiple adenomatous polyposis of the large intestine, multiple osteomas, dental abnormalities, fibrous dysplasia of the skull, fibromas, desmoid tumors, epidermoid cysts, a number of malignant tumors, and ST. ${ }^{[49,50]}$ The affected gene (APC) is located on the long arm of chromosome 5. ${ }^{[49]}$ Gardner's syndrome has been accepted a variant of familial adenomatosis polyposis (FAP), rather than a distinct subtype of the disease. ${ }^{[51]}$ Garden's Syndrome is used to identify the clinical manifestations of cases with FAP in whom the extra-intestinal features, such as osteomas, skin tumors, and soft-tissue tumors are especially prominent. At least $10-15 \%$ of patients with FAP develop desmoids tumors that usually located in the abdominal wall and intra-abdominally. ${ }^{[51]}$ Desmoid tumors are one of the most important causes of mortality in patients with FAP. ${ }^{[51]}$ Presence of osteomas is required to make the diagnosis of Gardner's syndrome. ${ }^{[52]}$ Osteomas are usually asymptomatic and are typically localized in the mandible, but can also appear in the skull and long bones. Skin tumors include epidermal cysts, lipomas, leiomyomas, and fibromas. Although not initially described by Gardner, congenital hypertrophy of the retinal pigmented epithelium is also a common manifestation of FAP. ${ }^{[53]}$ Oral findings are ST, esp. odontomas, osteomas of the jaw and impacted teeth and that present in nearly $30 \%$ of patients with Gardner syndrome. ${ }^{[49,52]}$

\section{Fabry disease}

Fabry's disease is a rare X-linked metabolic lysosomal storage disease that caused by a deficiency of the lysosomal enzyme alpha-galactosidase A (AGA). ${ }^{[54]}$ The underlying reason is the mutations in the gene encoding AGA. The first symptoms of Fabry's disease are usually febrile episodes, painful acroparesthesia, and gastrointestinal upset which are noticed during childhood. ${ }^{[54-56]}$ The main problem is the accumulation of glycophospholipids at the different organs and tissues. The disease leads to various clinical findings, including cardiomyopathy, high blood pressure, angiokeratomas, renal insufficiency, renal failure, cornea verticillata, neropathia, tinnitus, and vertigo. ${ }^{[55]}$ Oral findings have been reported in a limited number of studies. At this disease intraoral and perioral telangiectasias, angiokeratomas, cysts or polyps of the maxillary sinuses can be seen. ${ }^{[56]}$ At the previous reports multiple supernumerary, impacted and unerupted teeth, and dental malocclusion in patients with Fabry's disease were also described. ${ }^{[57,58]}$

\section{Ellis-Van Creveld Syndrome (Chondroectodermal Dysplasia)}

Ellis-van Creveld syndrome is an autosomal recessive disorder caused by mutation in the EVC and also EVC2 gene that map to the chromosome 4p16. ${ }^{[59]}$ The prevalence of the syndrome is about $7 / 1,000,000 .{ }^{[60]}$ The affected tissues are mainly ectodermal components such as hairs, nails and enamel. ${ }^{[5,60]}$ The characteristic features of the syndromeincludes; post-axial polydactyl, genitourinary abnormalities at males (epispadias, hypospadias, cryptorchidism), atrial septal defect, short-limbed dwarfism that identifiable at birth, short ribs, malformation of the wrist bones, cleft palate and ST (natal teeth). ${ }^{[61]}$ In terms of dentition, partial cleft lip, defect in alveolar ridge and ST formation are clinical findings and especially teeth may already be erupted at birth (natal teeth) and they exfoliate prematurely. ${ }^{[62]}$

\section{Trico-Rhino-Phalangeal Syndrome}

The Tricho-Rhino-Phalangeal Syndromes is an autosomal-dominant disorder that characterized by abnormalities of the hair, face, and skeletal system. ${ }^{[63]}$ The clinical manifestations of the syndrome are fine and sparse scalp hair, cone-shaped epiphyses of the middle phalanges of some fingers and toes, laterally sparse eyebrows, sparse eyelashes, a thin upper lip with vermilion border, pear-shaped broad nose, a long and flat philtrum, occasionally large and protruding ears, and hip malformations. ${ }^{[64]}$ Three types of the syndrome have been classified according to their clinical differences and cytogenetic abnormalities. TRPS type I also called as Giedion syndrome is caused by deletion or heterozygous mutations in the TRPS1 gene on chromosome $8 q 24 .{ }^{[65]}$ Besides the cardinal features of the syndrome dental abnormalities such as microdontia, delayed tooth eruption, ST and malocclusion have been reported. ${ }^{[64]}$

\section{Rubinstein-Taybi Syndrome}

Rubinstein-Taybi Syndrome (RTS) is a rare multiple congenital syndrome characterized by distinctive facial features, moderate to severe learning difficulties, broad thumbs, and great toes. ${ }^{[6]}$ The RTS was first described in 1963, with the main clinical features such as short-broad thumbs and great toes, mental 
disability, small head, cryptorchidisim in males, histories of recurrent respiratory infections and particular facial abnormalities. ${ }^{[67]}$ The affected people have a "beaked-shaped" nose, with a broad fleshy bridge, long and deviated septum protruding below the level of the nasal alae with an associated short columella. ${ }^{[66]}$ The newborn does not resemble typical facial appearance of RTS but characteristic face becomes obvious with age. Congenital cardiovascular and urinary tract system anomalies, as well as, tumors and coetaneous features like spontaneous keloids, nevus, café au lait spots, keratoses pilaris are among systemic complications of the syndrome. ${ }^{[67]}$ The diagnosis of RST is essentially made by clinical and radiological examination accompanied with detailed history taking. The incidence of clinically diagnosed individuals with RTS is about $8 \% .{ }^{[67]}$ The dentist play a great role since the presence of $\mathrm{ST}$ and talon cusps can be very useful.

\section{Nance-Horan Syndrome (Cataract-Dental Syndorme)} Nance-Horan syndrome is an X-linked syndrome involving both dental anomalies and ophthalmological findings. It is caused by mutations in the NHS gene on the chromosome Xp22. ${ }^{[68,69]}$ Until date, 26 mutations in the NHS gene have been described. Ophthalmological findings in affected males include bilateral severe congenital cataract that is usually leading to profound visual loss. Microphthalmia, nystagmus, and microcornea have also been reported..$^{\left[{ }^{[9]}\right.}$ Mental retardation, autism, and behavioral disturbance can be seen. Characteristic dysmorphic facial features include long, narrow facies, large anteverted pinnae, prominent nose and prominent nasal bridge. ${ }^{[68,69]}$ Dental abnormalities include supernumerary maxillary incisors (mesiodens), diastema between the teeth and screwdriver blade-shaped incisors.

\section{DISCUSSION}

Supernumerary teeth are common clinical and radiographic findings that are usually a component of the syndrome. ${ }^{[24-31]}$ They cause certain clinical problems such as crowding, displacement of a permanent tooth, failure to erupt, or dentigerous cyst formation. ${ }^{[1-3]}$ They may exhibit ectopic eruption, may be impacted or erupts spontaneously. There are different opinions about the treatment options of ST. ${ }^{[5]}$ Some authors suggested that if ST do not cause any discernable adverse effect on adjacent teeth and if no future orthodontic treatment foreseen, it is reasonable to recommend that immediate surgical intervention is not essential. ${ }^{[70,71]}$ Other suggested that ST have a tendency to resorb and disappear if left untreated. ${ }^{[72,73]}$ Treatment decision may affected from several factors, such as the ST are erupted or nonerupted, stage of the crown and root development, the distance between the ST and root of the adjacent teeth and the condition of the dentition (malocclusion, crowding, missing teeth). ${ }^{[70-72]}$

The physician must be careful when evaluating the significant craniofacial or non-craniofacial findings. Isolated cleft lip and/ or palate can cause ST and also it can be inherited. ${ }^{[26,32,33]}$ Short stature must cause the physician to suspect of EvC Syndrome, CCD and RTS. ${ }^{[43,57,66]}$ If delayed closure of the cranial sutures and hypoplastic or aplastic clavicles are seen together with ST then diagnose of the patient is probably CCD. ${ }^{[57]}$ On the other hand, short-limb dwarfism, cleft palate, post-axial polydactyly, malformation of the wrist bones, ectodermal dysplasia with dystrophic nails, short ribs, genitourinary abnormalities, congenital cardiac abnormalities are the main features of EvC Syndrome. ${ }^{[59-61]}$ Mental and growth retardation and especially broad thumbs and great toes should make physicians diagnose RTS. ${ }^{[66,67]}$

Ophthalmological findings (such as congenital cataract) and mental retardation helps to diagnose of NHS and also different skeletal findings such as cone-shaped epiphyses of phalangeal bones and hip malformations can make physician diagnose TRPS. ${ }^{[29,30,68,69]}$ If a patient have ST with the symptoms of metabolic diseases such as cardiovascular disease, renal dysfunction and corneal dystrophy with febrile episodes, painful acroparesthesia, gastrointestinal upset, cutaneous angiokeratomas, stroke at a young age the physician must suspect if the underlying genetic disorder is Fabry Disease. ${ }^{[54-58]}$ The patient with intestinal multiple adenomatous polyposis, multiple osteomas of the facial bones, cutaneous epidermoid cysts, desmoid tumors, fibrous hyperplasia of the skin and mesentery must remind the Gardner's Syndrome. ${ }^{[49-51]}$

\section{CONCLUSION}

Supernumerary teeth can be an important component of a distinctive disorder and at the same time they can be an important clue for early diagnosis. Certainly detecting the abnormalities early gives us to make correct management of the patient and also it is important for making well informed decisions about long-term medical care and treatments. 


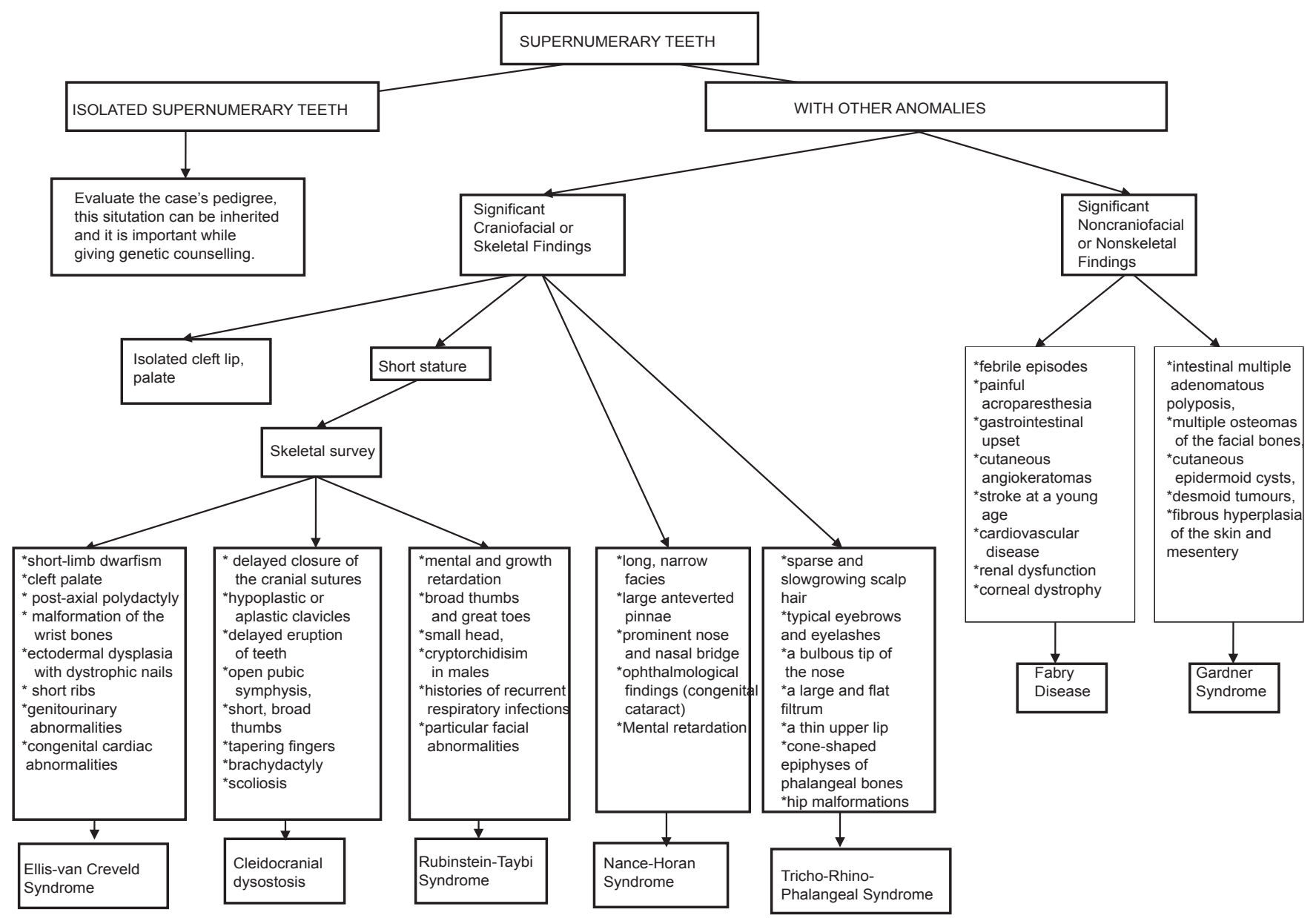

Supplemental file was prepared from the website "http://www.omim.org/"[74]

\section{REFERENCES}

1. Brook AH, Jernvall J, Smith RN, Hughes TE, Townsend GC. The dentition: The outcomes of morphogenesis leading to variations of tooth number, size and shape. Aust Dent J 2014;59 Suppl 1:131-42.

2. Anthonappa RP, King NM, Rabie AB. Aetiology of supernumerary teeth: A literature review. Eur Arch Paediatr Dent 2013;14:279-88.

3. Batra P, Duggal R, Parkash H. Non-syndromic multiple supernumerary teeth transmitted as an autosomal dominant trait. J Oral Pathol Med 2005;34:621-5.

4. Karadas M, Celikoglu M, Akdag MS. Evaluation of tooth number anomalies in a subpopulation of the North-East of Turkey. Eur J Dent 2014;8:337-41.

5. Cakan DG, Ulkur F, Taner T. The genetic basis of dental anomalies and its relation to orthodontics. Eur J Dent 2013;7:S143-7.

6. Leco Berrocal MI, Martín Morales JF, Martínez González JM. An observational study of the frequency of supernumerary teeth in a population of 2000 patients. Med Oral Patol Oral Cir Bucal 2007;12:E134-8.

7. Primosch RE. Anterior supernumerary teeth -Assessment and surgical intervention in children. Pediatr Dent 1981;3:204-15.

8. Davis PJ. Hypodontia and hyperdontia of permanent teeth in Hong Kong schoolchildren. Community Dent Oral Epidemiol 1987;15:218-20.

9. Giancotti A, Grazzini F, De Dominicis F, Romanini G, Arcuri C. Multidisciplinary evaluation and clinical management of mesiodens. J Clin Pediatr Dent 2002;26:233-7.

10. Mishra MB. Types of hyperodontic anomalies in permanent dentition: Report of 5 cases. Int J Clin Dent Sci 2011;2:15-21.

11. Bruning LJ, Dunlop L, Mergele ME. A report of supernumerary teeth in Houston, Texas school children. J Dent Child 1957;24:98-105.
12. Hall A, Onn A. The development of supernumerary teeth in the mandible in cases with a history of supernumeraries in the pre-maxillary region. J Orthod 2006;33:250-5.

13. Shah A, Gill DS, Tredwin C, Naini FB. Diagnosis and management of supernumerary teeth. Dent Update 2008;35:510-2, 514.

14. Hurlen B, Humerfelt D. Characteristics of premaxillary hyperodontia. A radiographic study. Acta Odontol Scand 1985;43:75-81.

15. Gábris K, Tarján I, Fábián G, Kaán M, Szakály T, Orosz M. Frequency of supernumerary teeth and possibilities of treatment. Fogorv Sz 2001;94:53-7.

16. Yusof WZ. Non-syndrome multiple supernumerary teeth: Literature review. J Can Dent Assoc 1990;56:147-9.

17. Foster TD, Taylor GS. Characteristics of supernumerery teeth in the upper central incisor region. Dent Pract Dent Rec 1969;20:8-12.

18. Waingade M, Gawande P, Aditya A, Medikeri RS. Pindborg tumor arising in association with an impacted supernumerary tooth in the anterior maxilla. J Mich Dent Assoc 2014;96:26-9.

19. Garvey MT, Barry HJ, Blake M. Supernumerary teeth - an overview of classification, diagnosis and management. J Can Dent Assoc 1999;65:612-6.

20. Ratson T. Diagnosis and treatment of supernumerary teeth in the premaxillary region: A literature review. Refuat Hapeh Vehashinayim 2013;30:26-30, 69.

21. Solares R, Romero MI. Supernumerary premolars: A literature review. Pediatr Dent 2004;26:450-8.

22. Marya CM, Kumar BR. Familial occurrence of mesiodentes with unusual fi ndings: Case reports. Quintessence Int 1998;29:49-51.

23. Van Buggenhout G, Bailleul-Forestier I. Mesiodens. Eur J Med Genet 2008;51:178-81.

24. Ramaglia L, Morgese F, Filippella M, Colao A. Oral and maxillofacial manifestations of Gardner's syndrome associated with growth hormone deficiency: Case report and literature review. Oral Surg Oral 
Med Oral Pathol Oral Radiol Endod 2007;103:e30-4.

25. Duncan BR, Dohner VA, Priest JH. The Gardner syndrome: Need for early diagnosis. J Pediatr 1968;72:497-505.

26. Lopes LD, Mattos BS, André M. Anomalies in number of teeth in patients with lip and/or palate clefts. Braz Dent J 1991;2:9-17.

27. Babaji P. Oral abnormalities in the Ellis-van Creveld syndrome. Indian J Dent Res 2010;21:143-5.

28. Regattieri LR, Parker JL. Supernumerary teeth associated with Fabry-Anderson's syndrome. Oral Surg Oral Med Oral Pathol 1973;35:432-3.

29. Giedion A. Tricho-rhino-phalangeal syndrome. Helv Paediatr Acta 1966;21:475-85.

30. Giedion A, Burdea M, Fruchter Z, Meloni T, Trosc V. Autosomal-dominant transmission of the tricho-rhino-phalangeal syndrome. Report of 4 unrelated families, review of 60 cases. Helv Paediatr Acta 1973;28:249-59.

31. Polymeropoulos MH, Ide SE, Wright M, Goodship J, Weissenbach J, Pyeritz RE, et al. The gene for the Ellis-van Creveld syndrome is located on chromosome 4p16. Genomics 1996:35:1-5.

32. Neiswanger K, Walker K, Klotz CM, Cooper ME, Bardi KM, Brandon CA, et al. Whorl patterns on the lower lip are associated with nonsyndromic cleft lip with or without cleft palate. Am J Med Genet A 2009;149A: 2673-9.

33. Cervenka J, Gorlin RJ, Anderson VE. The syndrome of pits of the lower lip and cleft lip and/or palate. Genetic considerations. Am J Hum Genet 1967;19:416-32.

34. Rizos M, Spyropoulos MN. Van der Woude syndrome: A review. Cardinal signs, epidemiology, associated features, differential diagnosis, expressivity, genetic counselling and treatment. Eur J Orthod 2004;26:17-24.

35. Bartzela TN, Carels CE, Bronkhorst EM, Kuijpers-Jagtman AM. Tooth agenesis patterns in unilateral cleft lip and palate in humans. Arch Oral Biol 2013;58:596-602.

36. Bohn A. Dental anomalies in harelip and cleft palate. Acta Odontol Scand 1963;21:1-114.

37. Mundlos S. Cleidocranial dysplasia: Clinical and molecular genetics. J Med Genet 1999;36:177-82.

38. McNamara CM, O'Riordan BC, Blake M, Sandy JR. Cleidocranial dysplasia: Radiological appearances on dental panoramic radiography. Dentomaxillofac Radiol 1999;28:89-97.

39. Li Y, Pan W, Xu W, He N, Chen X, Liu H, et al. RUNX2 mutations in Chinese patients with cleidocranial dysplasia. Mutagenesis 2009;24:425-31

40. Golan I, Baumert U, Hrala BP, Müssig D. Dentomaxillofacial variability of cleidocranial dysplasia: Clinicoradiological presentation and systematic review. Dentomaxillofac Radiol 2003;32:347-54.

41. Yamamoto H, Sakae T, Davies JE. Cleidocranial dysplasia: A light microscope, electron microscope, and crystallographic study. Oral Surg Oral Med Oral Pathol 1989;68:195-200.

42. Becker A, Lustmann J, Shteyer A. Cleidocranial dysplasia: Part 1 - General principles of the orthodontic and surgical treatment modality. Am J Orthod Dentofacial Orthop 1997;111:28-33.

43. Koch PE, Hammer WB. Cleidocranial dysostosis: Review of the literature and report of case. J Oral Surg 1978;36:39-42.

44. Tasar F, Bulut E, Tümer C, Saysel M, Muhtarogullari M. Cleidocranial dysplasia. Case report. Aust Dent J 1995;40:352-6.

45. Shankar YU, Reddy R, Swetha D. Cleidocranial dysplasia: A case report. Int J Contemp Dent 2011;2:73-5.

46. Mundlos S, Mulliken JB, Abramson DL, Warman ML, Knoll JH, Olsen BR. Genetic mapping of cleidocranial dysplasia and evidence of a microdeletion in one family. Hum Mol Genet 1995;4:71-5.

47. Cohen MM Jr. Biology of RUNX2 and Cleidocranial Dysplasia. J Craniofac Surg 2013;24:130-3.

48. Jensen BL, Kreiborg S. Development of the dentition in cleidocranial dysplasia. J Oral Pathol Med 1990;19:89-93.

49. Amla B, Banu GK, Cigdem O. Oral and maxillofacial manifestions of Gardner's syndrome: Case report. Acta Stomatol Croat 2009;43:60-5.

50. Patel H, Rees RT. Unicystic ameloblastoma presenting in Gardner's syndrome: A case report. Br Dent J 2005;198:747-8.

51. Gómez García EB, Knoers NV. Gardner's syndrome (familial adenomatous polyposis): A cilia-related disorder. Lancet Oncol 2009;10:727-35.

52. Gorlin RJ, Pindborg JJ, Cohen MM. Syndromes of the Head and Neck. $2^{\text {nd }}$ ed. New York: McGraw-Hill; 1976. p. 324-8.

53. Murgic J, Kirac I, Soldic Z, Tomas D, Zovak M, Bolanca A, et al. Familial adenomatous polyposis in three generations of a single family: A case study. Case Rep Oncol 2014;7:349-56.

54. Baccaglini L, Schiffmann R, Brennan MT, Lancaster HE Jr, Kulkarni AB, Brahim JS. Oral and craniofacial findings in Fabry's disease: A report of 13 patients. Oral Surg Oral Med Oral Pathol Oral Radiol Endod 2001;92:415-9.

55. Sestito S, Ceravolo F, Concolino D. Anderson-Fabry disease in children. Curr Pharm Des 2013;19:6037-45.

56. Young WG, Pihlstrom BL, Sauk JJ Jr. Granulomatous gingivitis in Anderson-Fabry disease. J Periodontol 1980;51:95-101.

57. Brindley HP, Archard HO, Alling CC, Jurgens PE, Jurgens EH. Case 11, Part 2. Angiokeratoma corporis diffusum (Fabry's disease). J Oral Surg 1975;33:199-205.

58. Davey PG. Fabry disease: A survey of visual and ocular symptoms. Clin Ophthalmol 2014;8:1555-60.

59. Alves-Pereira D, Berini-Aytés L, Gay-Escoda C. Ellis-van Creveld syndrome. Case report and literature review. Med Oral Patol Oral Cir Bucal 2009;14:E340-3.

60. Atasu M, Biren S. Ellis-van Creveld syndrome: Dental, clinical, genetic and dermatoglyphic findings of a case. J Clin Pediatr Dent 2000;24:141-5.

61. Bhat YJ, Baba AN, Manzoor S, Qayoom S, Javed S, Ajaz H. Ellis-van Creveld syndrome with facial hemiatrophy. Indian J Dermatol Venereol Leprol 2010;76:266-9.

62. Ruiz-Perez VL, Tompson SW, Blair HJ, Espinoza-Valdez C, Lapunzina P, Silva EO, et al. Mutations in two nonhomologous genes in a head-to-head configuration cause Ellis-van Creveld syndrome. Am J Hum Genet 2003;72:728-32.

63. Momeni P, Glöckner G, Schmidt O, von Holtum D, Albrecht B, Gillessen-Kaesbach $G$, et al. Mutations in a new gene, encoding a zinc-finger protein, cause tricho-rhino-phalangeal syndrome type I. Nat Genet 2000;24:71-4.

64. St-Jacques B, Hammerschmidt M, McMahon AP. Indian hedgehog signaling regulates proliferation and differentiation of chondrocytes and is essential for bone formation. Genes Dev 1999;13:2072-86.

65. Ishii T. Tricho-rhino-phalangeal syndrome, type I. Ryoikibetsu Shokogun Shirizu 2001;34:752-4.

66. Rubinstein JH, Taybi H. Broad thumbs and toes and facial abnormalities. A possible mental retardation syndrome. Am J Dis Child 1963;105:588-608.

67. Allanson JE. Rubinstein-Taybi syndrome: The changing face. Am J Med Genet Suppl 1990;6:38-41.

68. Tug E, Dilek NF, Javadiyan S, Burdon KP, Percin FE. A Turkish family with Nance-Horan Syndrome due to a novel mutation. Gene 2013;525:141-5.

69. Hong N, Chen $\mathrm{YH}, \mathrm{Xie} \mathrm{C}, \mathrm{Xu}$ BS, Huang H, Li X, et al. Identification of a novel mutation in a Chinese family with Nance-Horan syndrome by whole exome sequencing. J Zhejiang Univ Sci B 2014;15:727-34.

70. Toureno L, Park JH, Cederberg RA, Hwang EH, Shin JW. Identification of supernumerary teeth in 2D and 3D: Review of literature and a proposal. J Dent Educ 2013;77:43-50.

71. Koch H, Schwartz O, Klausen B. Indications for surgical removal of supernumerary teeth in the premaxilla. Int J Oral Maxillofac Surg 1986;15:273-81.

72. Munns D. A case of partial anodontia and supernumerary tooth present in the same jaw. Dent Pract Dent Rec 1967;18:34-7.

73. Shanmugha Devi G, Arangannal P, Muthu MS, Nirmal L. Supernumerary teeth associated with primary and permanent teeth: A case report. J Indian Soc Pedod Prev Dent 2002;20:104-6.

74. Supplemental file was prepared from the website "http://www.omim.org/"

\begin{tabular}{|l|l|}
\hline \multicolumn{2}{|c|}{ Access this article online } \\
\hline Quick Response Code: & Website: \\
& www.eurjdent.com \\
& \\
\end{tabular}

